\title{
Article \\ Root Canal Cleaning after Different Irrigation Techniques: An Ex Vivo Analysis
}

\author{
Federica Di Spirito ${ }^{1, *(\mathbb{D})}$, Massimo Pisano ${ }^{1}$, Mario Caggiano ${ }^{1}$, Prashant Bhasin ${ }^{2}$, Roberto Lo Giudice ${ }^{3} \mathbb{D}$ \\ and Dina Abdellatif 4
}

check for updates

Citation: Di Spirito, F.; Pisano, M.; Caggiano, M.; Bhasin, P.; Lo Giudice, R.; Abdellatif, D. Root Canal Cleaning after Different Irrigation Techniques: An Ex Vivo Analysis. Medicina 2022, 58, 193. https:// doi.org/10.3390/medicina58020193

Academic Editor: Joseph Nissan

Received: 31 December 2021

Accepted: 24 January 2022

Published: 27 January 2022

Publisher's Note: MDPI stays neutral with regard to jurisdictional claims in published maps and institutional affiliations.

Copyright: (C) 2022 by the authors. Licensee MDPI, Basel, Switzerland. This article is an open access article distributed under the terms and conditions of the Creative Commons Attribution (CC BY) license (https:// creativecommons.org/licenses/by/ $4.0 /)$.
1 Department of Medicine, Surgery and Dentistry, Schola Medica Salernitana, University of Salerno, Via S. Allende, 84081 Baronissi, SA, Italy; pisano.studio@virgilio.it (M.P.); macaggiano@unisa.it (M.C.)

2 Department of Conservative Dentistry \& Endodontics, Sudha Rustagi College of Dental Sciences and Research Faridabad, Faridabad 121002, India; drprashant.bhasin@gmail.com

3 Department of Clinical and Experimental Medicine, University of Messina, 98122 Messina, ME, Italy; roberto.logiudice@unime.it

4 Department of Endodontics, Faculty of Dentistry, University of Alexandria, Alexandria 21545, Egypt; dinaabdellatif81@gmail.com

* Correspondence: fdispirito@unisa.it

\begin{abstract}
Background and Objectives: The endodontic space is a complex area on both micro and macro levels; therefore, traditional irrigation techniques may not guarantee a complete cleaning of such a complicated tridimensional system. The presented ex vivo study aimed to evaluate root canal cleanliness, obtained through an equal volume of traditionally applied sodium hypochlorite ( $\mathrm{NaOCl})$, compared to ultrasonically activated $\mathrm{NaOCl}$ and ultrasonically activated $\mathrm{NaOCl}$ that had undergone intracanal heating $\mathrm{NaOCl}$. Materials and Methods: A total of 60 freshly extracted human mandibular premolars underwent root sample length standardization $(18 \mathrm{~mm})$, root canal preparation and, based on the irrigation method employed, were randomly and equally assigned to three study groups, composed of root samples treated with ultrasonically activated $\mathrm{NaOCl}$, ultrasonically activated $\mathrm{NaOCl}$ that had undergone intracanal heating and traditionally applied $\mathrm{NaOCl}$. The root specimens were subsequently fixated with $4 \%$ buffered formalin solution and decalcified in Morse liquid. A total often 6-micron-thick serial cross-sections were obtained, dyed using hematoxylin and eosin and examined through an optical microscope at $40 \times, 100 \times$, and $200 \times$. Results: Ultrasonically activated $\mathrm{NaOCl}$ that had undergone intracanal heating showed a significantly smaller amount of debris compared to ultrasonically activated and traditionally applied $\mathrm{NaOCl}$ groups ( $p$ value $<0.05$ ) Conclusions: Root canal cleanliness saw significant enhancements by ultrasonically activated $\mathrm{NaOCl}$ that had undergone intracanal heating.
\end{abstract}

Keywords: cleaning; endodontics; histology; internal heating; ultrasonic activation

\section{Introduction}

When teeth are diagnosed with inflamed vital pulps or infected with necrotic pulp tissues, the major aim of chemo-mechanical preparation is to target dissolving pulp tissue and dysrupt microbial biofilm. In particular, disinfection procedure should not only be confined to the major root canal space, but also reach the attached lateral canal system [1-4]. A complex lateral system like this includes macro-anatomies, in the form of lateral canals, isthmus, loop, delta and ramifications, as well as micro-anatomy, as the dentinal tubules. Accordingly, root canal irrigation, performed with a common syringe and needle, may not be able to produce the required shear stress, nor permit proper irrigant infiltration into lateral macro- and micro-anatomies [5], thus indirectly determining the persistence of residual pulp tissue or biofilm and eventually leading to persistent infections or reinfections [6,7] and to endodontic therapy failure in the complex lateral system. 
Consequently, in view of subduing such shortcomings, endodontic research has focused, in recent years, on developing strategies to activate irrigation, to which end several techniques, including subsonic, sonic, ultrasonic, laser and manual dynamic ones, have been tested with no definitive results $[5,8,9]$. Such contrasting results may be partially attributable to the heterogeneity of canal mechanical preparation systems, length of irrigant activation and outcome of measurement processing among the studies.

The use of extra-orally heated canal irrigants, particularly sodium hypochlorite $(\mathrm{NaOCl})$, is a well-known strategy for boosting pulp tissue solving effect $[10,11]$. However, the required buffering temperature may render this technique less effective in clinical use compared to in vitro applications. In order to overcome this setback, an alternative approach, specifically internal heating, was developed, allowing sodium hypochlorite to be heated, at controlled temperatures, within root canals, using heat carrier tips [12]. Notably, recent studies have shown that intracanal heating of $\mathrm{NaOCl}$ results in a drastic reduction in pulp tissue and microbial biofilm debris persistence onthe treated root canal walls when compared to irrigation with pre-heated $\mathrm{NaOCl}[13,14]$.

Given these considerations, the current ex vivo study aimed to evaluate, at a microscopic level, in conservatively shaped root canals, root canal cleanliness obtained through an equal volume of traditionally applied $\mathrm{NaOCl}$, compared to ultrasonically activated $\mathrm{NaOCl}$ and ultrasonically activated $\mathrm{NaOCl}$ that had undergone intracanal heating. The null hypothesis was that there was no significant difference among the three irrigation techniques applied.

\section{Materials and Methods}

The present study was approved by the Institutional Review Board and the local Ethics Committee. Written informed consent forms were gathered from all of the participants.

\subsection{Specimen Collection}

Sixty human mandibular premolars, freshly extracted as part of the orthodontic therapy plan, underwent periodontal tissues detachment, using a curette, immediately after tooth extraction, and were collected in separate vials, containing $5 \mathrm{~mL}$ of $10 \%$ formalin solution. The validity of the experimental design was expressed beforehand.

\subsection{Root Canal Preparation}

The collected teeth were slitted at the level of the cemento-enamel junction to create root samples of a standardized length $(18 \mathrm{~mm}$ ). A K-file $10 \mathrm{~mm}$ size (Hyflex, Coltene/ Whaldedent, Altstatten, Switzerland) was placed in each root canal until it was seen via the apex, and the working length was determined by deducting $0.5 \mathrm{~mm}$ from this measurement. Nickel-titanium rotary instruments, specifically 10/0.05 and 20/0.05 file instruments (Hyflex EDM, Coltene/Whaldedent, Altstatten, Switzerland), were exclusively employed on the entire working length to deliberately establish a conservative shaping of the root canals. Throughout the entire canal shaping, irrigation was performed with a total of $5 \mathrm{~mL}$ of $3 \% \mathrm{NaOCl}$, via a 30 G needle in a disposable syringe, renewed every minute, for each root canal. Subsequently, root canals were rinsed with sterile saline, further irrigated with $3 \mathrm{~mL}$ of 17\% EDTA for $1 \mathrm{~min}$ to eliminate the smear layer and lastly rinsed with $3 \mathrm{~mL}$ of sterile saline.

The 60 specimens were randomly and equally assigned to three groups $(n=20)$, composed of root samples treated with ultrasonically activated $\mathrm{NaOCl}$ (group A), ultrasonically activated $\mathrm{NaOCl}$ that had undergone intracanal heating (group B) and traditionally applied $\mathrm{NaOCl}$ (group C). The roots were tinted with nail varnish to avert irrigant extrusion. An equal volume of irrigant, $3 \% \mathrm{NaOCl}$ (CanalProTM 3\%, Coltene/Whaledent, Altstatten, Switzerland was injected into the root canals, using a 30G side-vented needle (CanalProColtene/Whaledent, Altstatten, Switzerland), at $2 \mathrm{~mm}$ from the working length, in the three groups. 
For the ultrasonically activated $\mathrm{NaOCl}$ group (group $\mathrm{A}$ ), $\mathrm{NaOCl}$ activation was performed through an ultrasonic file, connected to a cordless ultrasonic generator (Ultra smart ultrasonic activator, Coxo, Foshan City, China). The activation regimen comprehended eight cycles ( $20 \mathrm{~s}$ each), with $1 \mathrm{~mL}$ of irrigant freshened during each cycle. The ultrasonic tip was situated at $2 \mathrm{~mm}$ from the working length.

In ultrasonically activated $\mathrm{NaOCl}$ that had undergone intracanal heating (group B), ultrasonic activation was conducted as previously described and preceded by intracanal heating. The internal heating was performed for $8 \mathrm{~s}$ using a System-B heat source XFtip $(30 / 0.04)$ at $180{ }^{\circ} \mathrm{C}$ (Kavo Kerr, CA, USA) and was positioned at $3 \mathrm{~mm}$ from the working length.

The traditionally applied $\mathrm{NaOCl}$ group (group C) specimens were irrigated with $8 \mathrm{~mL}$ of $\mathrm{NaOCl}$ through a disposable syringe and needle at a $2 \mathrm{~mL} / \mathrm{min}$ pace.

\subsection{Evaluation of Root Canal Walls Cleanliness}

Thereafter, specimens were dried out and fixated, using $4 \%$ buffered formalin solution for $48 \mathrm{~h}$ and rinsed beneath running water for one hour. Then, samples were soaked in Morse liquid to reach decalcification for four weeks, with the solution being replenished every two days. Six micron-thick serial cross-sections were obtained from the roots, based on a previously applied protocol $[15,16]$. Ten serial sections, at $2-5 \mathrm{~mm}$ from the apex of the root canal, were dyed, using hematoxylin and eosin.

Subsequently, obtained sections were examined under an optical microscope (OptiKa TB 290, Optika, Turin, Italy), at 40×, 100× and 200×, using the dedicated Otpika Vision Lite software. Two independent, blinded, calibrated operators graded the quantity of pulp tissue debris in each section, based on the following criteria: grade 1-detectable debris on $75-100 \%$ of the area; grade 2 - debris on $50-74 \%$ of the entire area; grade 3 - debris on $25-49 \%$ of the entire area; grade $4-$ debris $<24 \%$ throughout the area. In case of disagreement between investigators, a third one evaluated the samples; final grading was accomplished by discussion among investigators.

\subsection{Data Presentation and Statistical Analysis}

Frequency distribution of persisting pulp tissue and microbial biofilm debris was presented as lambda scores. Non-parametric tests were used for multiple comparisons among groups (Kruskal-Wallis). Additionally, Mann-Whitney test was employed for comparisons between pairs of groups.

\section{Results}

Ultrasonically activated $\mathrm{NaOCl}$ that had undergone intracanal heating (group B) manifested no or $<25 \%$ debris for all of the sections (lambda 0.025 ), whereas the ultrasonically activated $\mathrm{NaOCl}$ group (group A) showed debris $>25 \%$ in multiple sections and $>50 \%$ in the remaining ones (lambda 0.0001 ). The traditionally applied $\mathrm{NaOCl}$ group (group C) revealed debris $>50 \%$ in all of the sections.

Ultrasonically activated irrigation preceded by intracanal heating resulted in significantly cleaner canals ( $p$ value $<0.05$ ) compared to ultrasonically activated irrigation alone and to syringe and needle irrigation (Figures 1 and 2). 


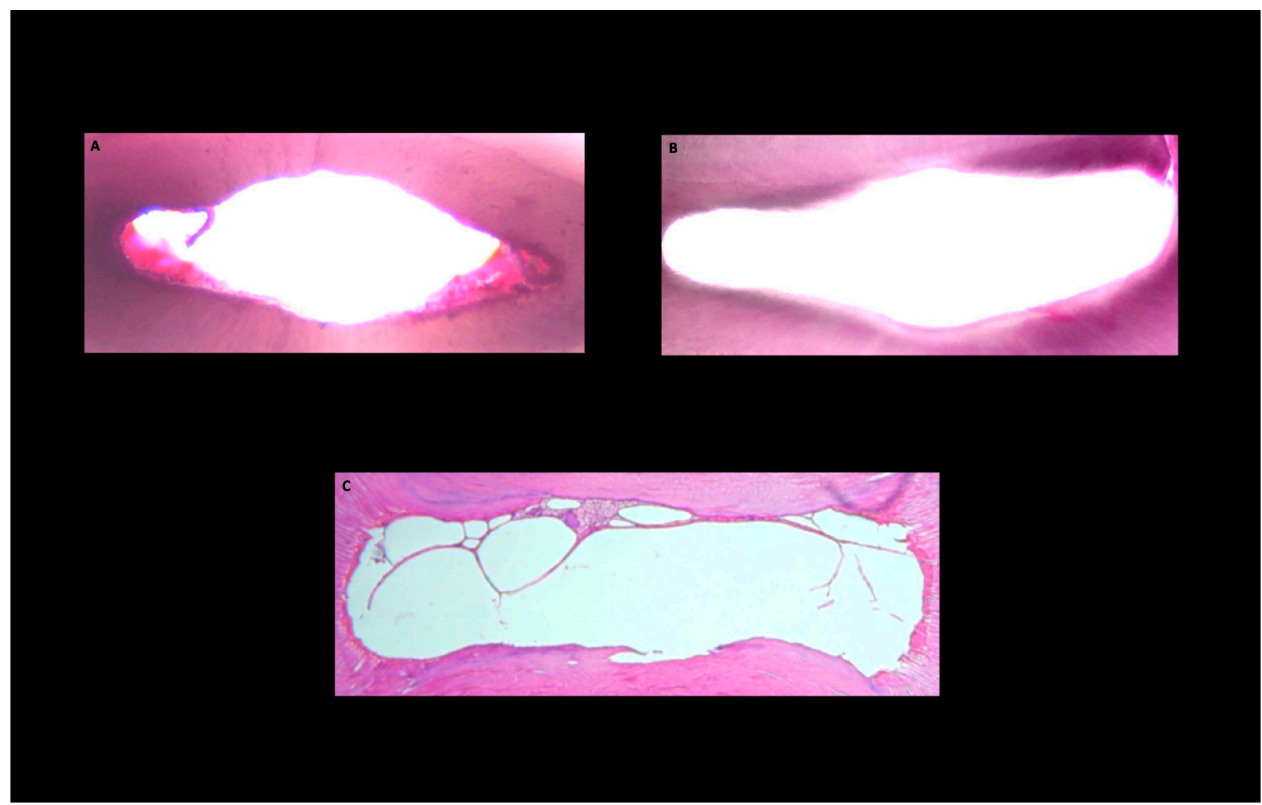

Figure 1. Histological images of the cross-sections obtained from the middle third of the root canal area after root canal preparation. Pulp tissue and microbial biofilm debris persisting and root canal wall protruding into the canal lumen (white) in ultrasonically activated (group A), ultrasonically activated preceded by intracanal heating (group B) and traditionally applied (group C) $\mathrm{NaOCl}$ groups.

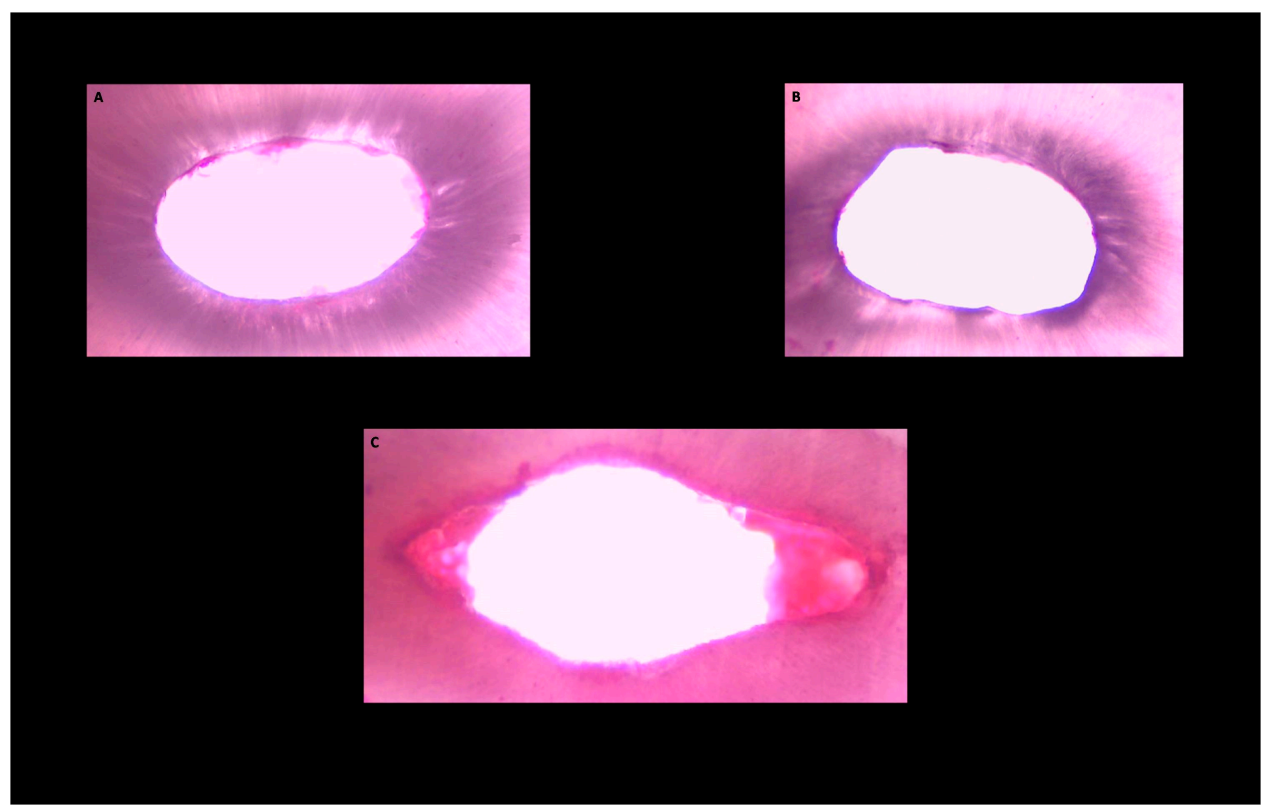

Figure 2. Histological images of the of the cross-sections obtained from the apical third of the root canal area after root canal preparation. Pulp tissue and microbial biofilm debris persisting and root canal wall protruding into the canal lumen (white) in ultrasonically activated (group A), ultrasonically activated preceded by intracanal heating (group B) and traditionally applied (group C) $\mathrm{NaOCl}$ groups.

\section{Discussion}

The main purpose of endodontic treatment is the removal, as complete as possible, of damaged pulp tissues and microbial biofilm from the complex endodontic system [14,15]. Considering that the root canal system comprises the macroscopic anatomy of the major canal and lateral ones, along with ramifications, loops, isthmuses, deltas, as well as the 
so-called microscopic anatomies, as the dentinal tubules, for effective endodontic cleaning, irrigants should be able to penetrate such complicated root anatomies [5].

Ordinarily, bacteria can survive either as independent free-floating cells, in planktonic state, or as members of colonized surface-attached microbial communities, enclosed in a self-produced extracellular matrix that connects cells, overall identified as biofilm [17]. Biofilm bacteria usually shows a greater resistance to antimicrobial agents, up to 1000-fold higher, compared to that reported for the same microorganisms in fluid suspension $[17,18]$. Currently, the most common and effective strategy for counteracting biofilm in root canals consists of mechanical instrumentation and irrigant activation, leading to biofilm elimination [17].

It is well established that contemporary mechanical preparation strategies are not able to adequately reach root canal walls, thus leaving residual tissue and microbial residues inside the root canal system [19-24], and, consequently, negatively affect endodontic treatment outcomes, secondary to potential persistent infection and re-infection [17]. Therefore, it appears essential to improve irrigation procedure to subdue the inadequacy of current instrumentation techniques.

Irrigation efficacy can be improved by employing activated irrigants; for instance, an easy way to activate $\mathrm{NaOCl}$ is its pre-heating to a temperature of $50{ }^{\circ} \mathrm{C}$. Pre-heated $\mathrm{NaOCl}$ solution has been proved to have higher antimicrobial effect and tissue dissolving capabilities $[5,12,13]$. Nevertheless, injecting pre-heated $\mathrm{NaOCl}$ into the root canal also has its constraints. The human body, in fact, can rapidly buffer $\mathrm{NaOCl}$ temperature, thusreducing the acquired heat empowered efficacy benefits [13]. Accordingly, it may be more convenient to heat $\mathrm{NaOCl}$ irrigant straight inside the root canal, by the means of heat carriers. Correspondingly, previous studies have highlighted that intracanal heating of $\mathrm{NaOCl}$ irrigant is more effective in eliminating residual organic tissues and removing hard tissue remnants from the major root canal area, when compared to pre-heated and non-heated $\mathrm{NaOCl}$ [14]. Irrigant activation, which can be obtained via sonic, ultrasonic, internal heating, or laser tools, has proved a remarkable enhancement in cleansing and disinfection of the endodontic system, being, therefore, considered an essential step in nonsurgical endodontic treatment. In accordance with such findings, the present ex vivo study outlined that ultrasonic activation subsequent to intracanal heating of $\mathrm{NaOCl}$ leads to significantly less remaining debris compared to ultrasonic irrigation of non-heated $\mathrm{NaOCl}$.

\section{Conclusions}

The endodontic space is a complex area, on both micro and macro levels; therefore, traditional irrigation techniques may not guarantee a complete cleaning of such a complicated tridimensional system. The irrigation technique employing ultrasonically activated $\mathrm{NaOCl}$ that has undergone intracanal heating may be considered easy to carry out in routine clinical procedures, as well as being economical, since it does not require specific equipment. Moreover, ultrasonically activated $\mathrm{NaOCl}$ that has undergone intracanal heating irrigation, through the reduction in $\mathrm{NaOCl}$ viscosity, and a consequent higher penetration into dentinal tubules, has been proved to enhance antimicrobial effect, as well as tissue dissolving capabilities $[5,12,13]$, and can be performed with no restrictions regarding tooth anatomy orclinical situations. Furthermore, this irrigation technique may be considered highly effective, which is in agreement with other authors' findings, since the technique as applied in this study highlighted that root canal cleanliness was significantly enhanced by ultrasonically activated $\mathrm{NaOCl}$ that had undergone intracanal heating irrigation, as compared to ultrasonically activated and traditionally applied $\mathrm{NaOCl}$.

However, although, to the authors' knowledge, the present study is the first to assess from an hystological point of view these complex lateral macro- and micro-anatomies, following ultrasonically activated $\mathrm{NaOCl}$ that has undergone intracanal heating irrigation, especially combined to conservative shaping, and to compare root canal walls' cleanliness obtained via three different irrigation techniques, the small sample size means that if they are to strengthen such ex vivo observations, forthcoming investigations should compare 
the results obtained from the presented technique for a complex lateral canal system with those from other irrigant activation strategies, combined to conservative shaping, both in preclinical and in clinical settings.

Author Contributions: Conceptualization and methodology, F.D.S.; formal analysis, R.L.G.; investigation, D.A.; data curation, P.B., M.C. and M.P.; writing-original draft preparation, D.A.; writing-review and editing, F.D.S. All authors have read and agreed to the published version of the manuscript.

Funding: This research received no external funding.

Institutional Review Board Statement: The study was conducted in accordance with the Declaration of Helsinki, and approved by the Ethical Committee of the University Federico II of Naples, Naples, Italy, (Protocol 55/21 approved on 28 April 2021).

Informed Consent Statement: Informed consent was obtained from all subjects involved in the study.

Data Availability Statement: All the data are available from the corresponding author upon reasonable request.

Conflicts of Interest: The authors declare no conflict of interest.

$\begin{array}{ll}\text { Abbreviations } \\ \mathrm{NaOCl} & \text { sodium hypochlorite } \\ \mathrm{Ml} & \text { milliliters } \\ \mathrm{Mm} & \text { millimeters } \\ \text { EDTA } & \text { Ethylenediaminetetracetic acid } \\ \mathrm{G} & \text { Gauge } \\ \mathrm{H} & \text { Hours } \\ \mathrm{C} & \text { Degree Celsius }\end{array}$

\section{References}

1. Dioguardi, M.; Gioia, G.D.; Illuzzi, G.; Laneve, E.; Cocco, A.; Troiano, G. Endodontic irrigants: Different methods to improve efficacy and related problems. Eur. J. Dent. 2018, 12, 459-466. [CrossRef] [PubMed]

2. Zehnder, M. Root canal irrigants. J. Endod. 2006, 32, 389-398. [CrossRef] [PubMed]

3. Iandolo, A.; Pantaleo, G.; Malvano, M.; Simeone, M.; Amato, M. Nonsurgical management of complex endodontic cases with several periapical lesions: A case series. G. Ital. Endod. 2016, 30, 101-103. [CrossRef]

4. Neuhaus, K.W.; Liebi, M.; Stauffacher, S.; Eick, S.; Lussi, A. Antibacterial efficacy of a new sonic irrigation device for root canal disinfection. J. Endod. 2016, 42, 1799-1803. [CrossRef]

5. Amato, M.; Pantaleo, G.; Abdellatif, D.; Blasi, A.; Gagliani, M.; Iandolo, A. An in vitro evaluation of the degree of pulp tissue dissolution through different root canal irrigation protocols. J. Conserv. Dent. 2018, 21, 175-179. [CrossRef]

6. Yared, G.; Al Asmar Ramli, G. Antibacterial ability of sodium hypochlorite heated in the canals of infected teeth: An ex vivo study. Cureus 2020, 12, e6975. [CrossRef]

7. Neelakantan, P.; Cheng, C.Q.; Mohanraj, R.; Sriraman, P.; Subbarao, C.; Sharma, S. Antibiofilm activity of three irrigation protocols activated by ultrasonic, diode laser or Er:YAG laser in vitro. Int. Endod. J. 2015, 48, 602-610. [CrossRef]

8. Iandolo, A.; Abdellatif, D.; Amato, M.; Pantaleo, G.; Blasi, A.; Franco, V.; Neelakantan, P. Dentinal tubule penetration and root canal cleanliness following ultrasonic activation of intracanal-heated sodium hypochlorite. Aust. Endod. J. 2020, 46, 204-209. [CrossRef]

9. Gu, L.S.; Kim, J.R.; Ling, J.; Choi, K.K.; Pashley, D.H.; Tay, F.R. Review of contemporary irrigant agitation techniques and devices. J. Endod. 2009, 35, 791-804. [CrossRef]

10. Nagendrababu, V.; Jayaraman, J.; Suresh, A.; Kalyanasundaram, S.; Neelakantan, P. Effectiveness of ultrasonically activated irrigation on root canal disinfection: A systematic review of in vitro studies. Clin. Oral Investig. 2018, 22, 655-670. [CrossRef]

11. Malentacca, A.; Uccioli, U.; Mannocci, F.; Bhuva, B.; Zangari, D.; Pulella, C.; Lajolo, C. The comparative effectiveness and safety of three activated irrigation techniques in the isthmus area using a transparent tooth model. Int. Endod. J. 2018, 51, 35-41. [CrossRef] [PubMed]

12. Cunningham, W.T.; Balekjian, A.Y. Effect of temperature on collagen-dissolving ability of sodium hypochlorite endodontic irrigant. Oral Surg. Oral Med. Oral Pathol. 1980, 49, 175-177. [CrossRef]

13. Stojicic, S.; Zivkovic, S.; Qian, W.; Zhang, H.; Haapasalo, M. Tissue dissolution by sodium hypochlorite: Effect of concentration, temperature, agitation, and surfactant. J. Endod. 2010, 36, 1558-1562. [CrossRef] [PubMed]

14. Iandolo, A.; Amato, M.; Dagna, A.; Poggio, G.; Abdellatif, D.; Franco, V.; Pantaleo, G. Intracanal heating of sodium hypochlorite: Scanning electron microscope evaluation of root canal walls. J. Conserv. Dent. 2018, 21, 569-573. [CrossRef] 
15. Yared, G.; Ramli, G.A. Ex vivo ability of a noninstrumentation technique to disinfect oval-shaped canals. J. Conserv. Dent. 2020, 23, 10-14. [CrossRef] [PubMed]

16. Riccitiello, F.; Maddaloni, G.; D'Ambrosio, C.; Amato, M.; Rengo, S.; Simeone, M. Operating microscope: Diffusion and limits. G. Ital. Endod. 2012, 26, 67-72. [CrossRef]

17. Armencea, G.; Gheban, D.; Onisor, F.; Mitre, I.; Manea, A.; Trombitas, V.; Lazar, M.; Baciut, G.; Baciut, M.; Bran, S. Histological Change in Soft Tissue Surrounding Titanium Plates after Jaw Surgery. Materials 2019, 12, 3205. [CrossRef]

18. Mohammed, S.A.; Vianna, M.E.; Penny, M.R.; Hilton, S.T.; Mordan, N.J.; Knowles, J.C. Investigations into in situ Enterococcus faecalis biofilm removal by passive and active sodium hypochlorite irrigation delivered into the lateral canal of a simulated root canal model. Int. Endod. J. 2018, 51, 649-662. [CrossRef]

19. Barone, A.; Chatelain, S.; Derchi, G.; Di Spirito, F.; Martuscelli, R.; Porzio, M.; Sbordone, L. Effectiveness of antibiotics in preventing alveolitis after erupted tooth extraction: A retrospective study. Oral Dis. 2020, 26, 967-973. [CrossRef]

20. Lacerda, M.F.; Marceliano-Alves, M.F.; Pérez, A.R.; Provenzano, J.C.; Neves, M.A.; Pires, F.R.; Gonçalves, L.S.; Rôças, I.N.; Siqueira, J.F., Jr. Cleaning and shaping oval canals with three instrumentation systems: A correlative micro-computed tomographic and histologic study. J. Endod. 2017, 43, 1878-1884. [CrossRef]

21. Iandolo, A.; Ametrano, G.; Amato, M.; Rengo, S.; Simeone, M. IG-File: A novel tool to improve root canal cleaning and measurement of the apical foramen. G. Ital. Endod. 2011, 25, 72-81. [CrossRef]

22. Lauritano, D.; Moreo, G.; Carinci, F.; Della Vella, F.; Di Spirito, F.; Sbordone, L.; Petruzzi, M. Cleaning Efficacy of the XP-Endo ${ }^{\circledR}$ Finisher Instrument Compared to Other Irrigation Activation Procedures: A Systematic Review. Appl. Sci. 2019, 9, 5001. [CrossRef]

23. Iandolo, A.; Simeone, M.; Riccitiello, F. The preparation of coronal isthmus is a fundamental step for long term success. G. Ital. Endod. 2012, 26, 150-154. [CrossRef]

24. Iandolo, A.; Dagna, A.; Poggio, C.; Capar, I.; Amato, A.; Abdellatif, D. Evaluation of the actual chlorine concentration and the required time for pulp dissolution using different sodium hypochlorite irrigating solutions. J. Conserv. Dent. 2019, 22, 108-113. [CrossRef] 